\title{
Bringing animal ethics teaching into the public domain: the Animalogos experience
}

\author{
I Anna S Olsson, Nuno H Franco, Manuel Magalhães-Sant'Ana \\ Originally published in Climate change and sustainable development, pp 483-488, 2012.
}

\begin{abstract}
An increasing number of academic researchers blog - most as a form of science communication to a wider public. This tool is particularly interesting as it provides a way for scientists to communicate directly with a public rather than depending on journalists. When we launched Animalogos (animalogos.blogspot.com) in December 2009, our main aim was to establish a forum of communication for people working professionally with animal ethics and animal welfare, in order to provide a Portuguese-language professional perspective on issues previously almost exclusively commented on by animal rights and animal protection NGOs.
\end{abstract}

Increasingly, we have also integrated the blog into animal ethics teaching, where we now use it as the main examination tool in the animal ethics discipline of two courses: a postgraduate course in animal welfare and an undergraduate course in veterinary medicine. Individually, students have to write a comment to one of the existing blog posts, a comment which is published by the students themselves. In groups, they have to write a post on a topic of their own choice, which is published after revision.

For examination purposes, the texts thus produced by the students are evaluated as a short written essay. Whether to be anonymous or not is the students' own choice. Using the blog as a resource for teaching and examination started as a pilot project during the academic year 2010/11, during which the method was evaluated from the teachers' perspective.

The main advantages with involving students in the blog activity is that firstly students get to make a real contribution to the public debate and secondly that this draws attention to the blog. The main disadvantage we observed was that most posts written by students require substantial revision before they can be published, sometimes resulting in negative reactions from the students.

Continuing the project in 2011/12, we have asked feedback from students. Overall, they view the experience as positive and consider examination through writing for the blog preferable to traditional exams (written or oral), essays or oral presentations. More than half of the students would like this examination approach for more disciplines within the course they are taking. All respondents think that anonymity should be an option when they are writing for the blog. 


\section{:.:IIIIBMC}

\section{INTRODUCTION}

A blog (short for weblog) is a "web site that contains an online personal journal with reflections, comments, and often hyperlinks provided by the writer" (Merriam-Webster dictionary). Blogging is one of the many features of the internet-based communication means known as Web 2.0 which enables users to contribute with their own resources. While particularly prominent in entertainment and social interaction, Web 2.0 is increasingly being used as a learning tool (Sandars, 2007) both to enhance students' learning experience (Boulos et al. 2006) and to promote professional lifelong learning (e.g. Dale et al. 2011).

Most EurSAFE conference attendees have probably contacted with a blog at some point - as readers, writers or simply as consumers of mass media discussions of the phenomenon. An increasing number of scientists blog and they do it for a variety of reasons. Some are relatively personal and internal: a need for ventilating and sharing experiences of academic life beyond the coffee room of the own institution. But most science blogs are directed towards a wider audience and are a form of science communication.

The blog is particularly interesting as it provides a way for scientists to communicate directly with a public rather than depending on journalists - thus choosing themselves which topics to address and how to present them. When we launched Animalogos (animalogos.blogspot.com) in December 2009, our main aim was to establish a forum of communication for people working professionally with animal ethics and animal welfare, in order to provide a Portuguese-language professional perspective on issues previously almost exclusively commented on by animal rights and animal protection NGOs. The team behind the blog consists of a senior scientist in animal welfare and ethics and two PhD students in the same disciplines. In addition to working together in research, we share a passion for writing and communication, and all of us were already active on the Web 2.0 using other blogs or Facebook in a semi-professional context.

The professional perspective is a key feature of Animalogos and this was also the basis for involving the blog in our respective teaching of animal ethics to students of veterinary medicine and animal welfare. This approach is particularly relevant for final-year students, who are at a point in their career from which they will actually be acting professionals and our colleagues in less than a year. This means that on the one hand they have most of the required knowledge while on the other hand they need to practise the skills necessary to participate in the public discussion on controversial topics linked to their professions. Usually, these skills are practised through interactive exercises such as group discussions and role plays, whereas knowledge is examined in the form of essays, oral presentations or exams. However, we argue that keeping animal ethics within the closed classroom environment does not make full use of the potential that highly qualified students have of producing material that can contribute to an informed public discussion.

The aim with the present paper is to present our experience of using a thematic, academic/professional blog as a resource for animal ethics teaching. The paper is not intended as a detailed academic analysis of this endeavour but as a basic introduction and evaluation of an approach we have found useful and which we hope can inspire colleagues in other countries.

\section{HOW WE USE ANIMALOGOS IN TEACHING}

The blog is used in animal ethics teaching in two courses:

- MSc in Veterinary Medicine, Escola Universitária Vasco da Gama, Coimbra, Portugal (final-year students); Animalogos used in one edition (May 2011)

- Post-graduation course in Behaviour and Animal Welfare, Instituto Superior de Psicologia Aplicada, Lisbon, Portugal (adult learners with an animal-related profession); Animalogos used in two editions (Nov 2010, Nov 2011)

In both courses, writing for Animalogos serves as the examination for the students. This is preceded by a teaching period in which the students are exposed to the theoretical content of the respective disciplines, principally through lectures and the interactive on-line resource Animal Ethics Dilemma (Hanlon et al 2007). The objectives of the ethics discipline in the respective courses are presented in Box 1. 


\section{\#\#\#!IBMC}

The examination involves two tasks: individually students have to write a comment to an existing post on Animalogos and in groups of three they have to write a new post for later publication on the blog. An extensive tutorial is handed out to the students during the teaching period; this tutorial explains what to consider when writing for the blog as well as the main criteria used by teachers when evaluating students' performance (Box 1). Depending on the course, recommendations are also made in terms of topics to be explored. The final mark is calculated as $2 / 3$ of the score of the individual contribution plus $1 / 3$ of the group contribution.

Box 1. Teaching objectives for animal ethics. The text in blue indicate the aspects that are primarily covered by the blog writing exercise.

\section{Teaching objectives \\ MSc in Veterinary Medicine, EUVG}

Promote the students' critical thinking by inviting them to indentify, analyze and reflect on the different ethical questions involving the use of animals

Be able to discuss, confront different opinions and understand the point of view of other people

Be able to apply the veterinary Professional code of conduct

Develop a personal ethical reasoning based on correct observation of facts and values

\section{Post-graduation course in Behaviour and Animal Welfare, ISPA}

Know and be able to use the learning tool 'Animal Ethics Dilemma'.

Know the main philosophical basis for animal ethics: utilitarianism, relational view, animal rights, respect for nature, contractarianism.

Elaborate and recognize the individual ethical profile and its consistency when facing different ethical dilemmas

Promote the students' critical thinking by inviting them to indentify, analyze and reflect on the different ethical questions involving the use of animals

Analyze and discuss ethical dilemmas specific to the areas of farm animal production, companion animals, wild animals in captivity as well as environmental ethics
Box 2. Summary of the information provided as guidelines for the students when preparing their contributions to the blog.

\section{Ethical thinking when writing for Animalogos \\ When writing a text on ethics, the following is needed:}

- Appropriate use of technical and scientific knowledge

- Communication skills

- Ethical reflection with appropriate use of ethical principles and professional norms

\section{Ethical reflection is characterized by being:}

- $\quad$ Reflective : More than merely expressing an opinion; reflective equilibrium

- $\quad$ Coherent: Consistency; treat equally relevant facts/arguments equally

- Informed: Appropriate use of scientific, technical and legal knowledge

- Unbiased: Considering different viewpoints: Defending universal principles

\section{Evaluation of texts}

Evaluation is based on the following criteria:

1. Originality

2. Scholarly quality of the content

3. Language

4. Critical thinking

5. Additional enrichment through links, references and audiovisual material.

\section{THE STUDENT PERSPECTIVE}

To evaluate the students' perspective, an on-line survey was distributed by e-mail to the 21 participants in the second edition of the Postgraduate Course in Behaviour and Animal Welfare, ISPA, Lisbon in January 2012. The survey took place 1.5 month after the students had finished the discipline, and at the time of completing the survey they knew that they had been approved but did not know their final mark. During the week that the survey was open, 16 respondents completed the survey.

Familiarity with blogs: Prior to the course, the students were not very familiar with blogs in general (2 students read blogs once a week or more, 12 students read some type of blogs less than once a week, 4 students never read any type of blogs) or with Animalogos (12 students did not know the blog, 2 thought they had seen it before, 1 was an occasional reader). 


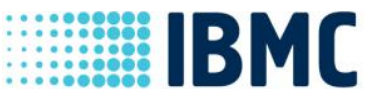

Blogs as a source of information: The students had an overall positive view of professional blogs in general and of Animalogos as regards accessibility (general 4.3; Animalogos 4.4; maximum score 5), credibility (general 3.9; Animalogos 4.2) and impartiality (general 3.2; Animalogos 3.6).

Examination using Animalogos: All students found it an overall positive (10 respondents) or very positive (6 respondents) experience. The majority of students expressed that they would like to be examined using this approach in other disciplines in the course (12 yes, 4 don't know/don't answer). They also consider examination through writing for the blog preferable/much preferable to traditional exams (written or oral), essays or oral presentations (average 4.2; maximum score 5).

Anonymity: The students expressed some ambiguity in relation to the question of making their identity public. When presented with the statement that revealing personal opinions publically is a potential problem, 7 students agree completely or partially whereas another 7 disagree completely or partially. All respondents think that anonymity should be optional when contributing to the blog as part of the examination.

Difficulties and advantages: As difficulties, several students expressed that their lack of experience with this evaluation method made them unsure about what was expected, and unsure what to do when the (ethical) view they expressed were different from that of the teacher(s). However, they also found the method innovative and appreciated the way that they were stimulated to make more general reflections on the topics addressed in the discipline.

\section{HOW THE TEACHING USE AFFECTS THE BLOG}

The effect of involving students on the blog dynamics can be evaluated through the statistics for page views as well as comments made to the blog. Both these measures show that the students contribute greatly to the dynamics and interactive nature of the blog.

The page view statistics show a distinct peak at each of the three periods in which the blog was used in teaching (Figure 1).

During 2010 and 2011, a total of 318 comments were made to different blog posts. Of these, 146 were written as part of a dialogue between an external contributor (the vast majority of which were students) and an Animalogos team member, 143 were comments written by one of the Animalogos team members to a post written by another team member and 29 written by other external contributors. Thus, dialogue with students represented approximately half of the discussion.

Figure 1. Page views per month May 2010-December 2011. Each of the three peaks corresponds to a period in which the blog was used for teaching.

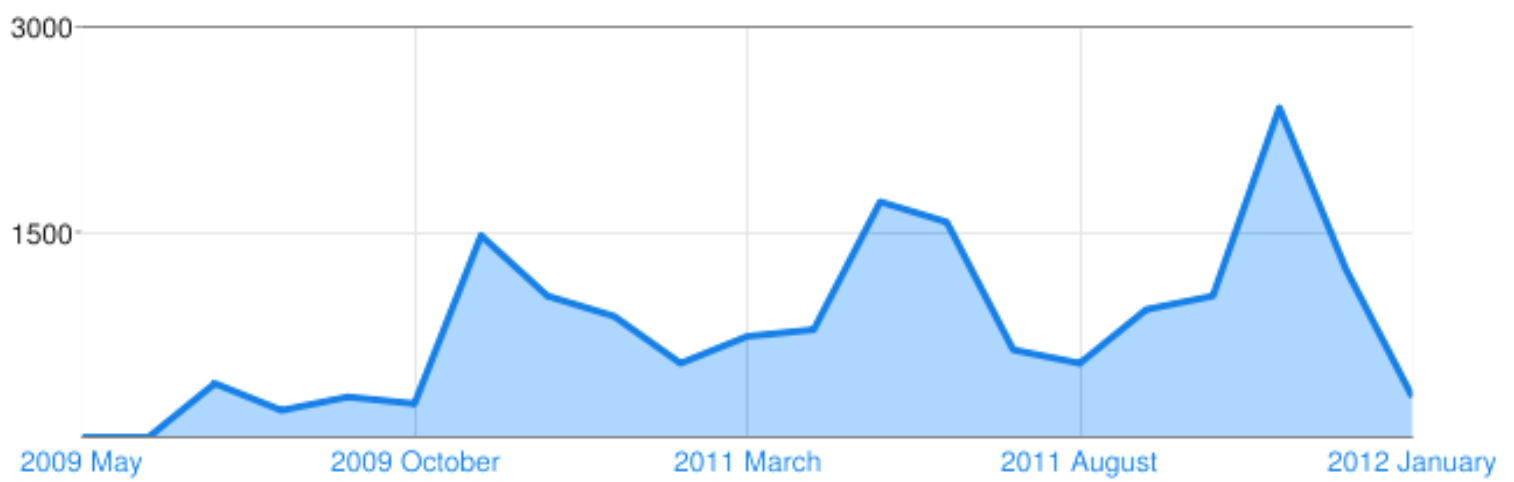




\section{DISCUSSION AND CONCLUSION}

Including Animalogos as a resource for teaching had several positive effects. In terms of blog dynamics and visibility, the number of page views doubled during the periods when the students used the blog in teaching and the public dialogues in which the students participate correspond to approximately half of the discussion on the blog. Having this kind of continuous interaction with the students enabled us to bring the teaching experience out of the classroom environment and to extend it in terms of time and space.

The students are generally positive to this form of examination and they appreciate the way that it stimulates them to develop an ethical reflection. It is very rewarding to realize that students prefer the experience of writing for the blog to having traditional exams, essays or oral presentations. For us as teachers, this examination form is more demanding than traditional written or oral exams. It is challenging and time-consuming to make a correct evaluation of texts that vary widely in content and form. To maintain the dynamics of the blog, we also need to keep up with and respond to comments as they appear on the blog. Additionally, the posts written by students often require substantial revision before publication.

However, the extra demand this places on us as teachers is compensated for by the contribution the students provide to the blog. They are clearly competent participants to the public discussion which they enrich with new ideas, perspectives and facts. From our perspective as blog editors, we see an immediate gain in increased dynamics, diversity and visibility, and we hope that some of the students also continue to read the blog after the course.

In terms of teaching objectives, the blog writing exercise tests primarily the students' capacity for critical thinking, argumentation and discussion, as this student comment summarizes: "Being evaluated through the writing of a comment and/or a post obliges one to reflect on the themes and stimulates thought in a way that is completely different from the typical study for an exam, in which one tends to focus on the topics addressed in class."

\section{REFERENCES}

Dale, V.H.M., Kinnison, T., Short, N., May S.A. and Baillie, S. (2011). Web 2.0 and the veterinary profession: current trends and future implications for lifelong learning. Veterinary Record 169: 467-471.

Hanlon, A.J., Algers, A., Dich, T., Hansen, T., Loor, H. and Sandøe, P. (2007). 'Animal Ethics Dilemma': an interactive learning tool for university and professional training. Animal Welfare 16(S1): 155-158.

Sandars, J. (2007). The potential of blogs and wikis in healthcare education. Education for Primary Care 18: 16-21.

Boulos, M.N.K., Maramba, I. and Wheeler, S. (2006). Wikis, blogs and podcasts: a new generation of Webbased tools for virtual collaborative clinical practice and education. BMC Medical Education 6: 41. 